\title{
Pengembangan Media Papin dan Koja (Papan Pintar dan Kotak Ajaib) Sebagai Media Pembelajaran Matematika
}

\author{
Muhammad Zaenal Fais ${ }^{1 *}$, Ikha Listyarini ${ }^{2}$, Ahmad Nashir Tsalatsa ${ }^{3}$ \\ 123 Pendidikan Sekolah Dasar. FIP. Universitas PGRI Semarang
}

\begin{abstract}
Abstrak
Penelitian ini bertujuan untuk mengetahui mengembangkan media papin dan koja yang valid dan mengetahui kelayakan media dalam pembelajaran matematika pada materi pembulatan bilangan siswa kelas IV SDN 1 Bugangan 02 Semarang. Penelitian ini menggunakan metodologi penelitian Research and Development (R\&D)

Keywords:

Pengembangan, papin dan koja matematika, pembelajaran. dengan langkah pencarian potensi dan masalah, pengumpulan data, desain produk, validasi desain, revisi desain, dan uji coba produk. Rata-rata hasil belajar siswa SDN Bugangan 02 Semarang saat pertemuan pertama sebesar 61,5 dan pada saat pertemuan kedua sebesar 79,2. Hasil tanggapan pada analisis ahli media 86,3\% sangat baik, ahli materi $82,6 \%$ sangat baik, angket keberterimaan siswa terhadap media papin dan koja 97\% sangat baik. Berdasarkan hasil tersebut dapat disimpulkan bahwa media papin dan koja layak digunakan dalam pembelajaran matematika karena sudah mencapai hasil belajar saat pertemuan pertama sebesar 61,5 dan pada saat pertemuan kedua sebesar 79,2. Berdasarkan hasil penelitian pengembangan ini, saran yang dapat peneliti sampaikan adalah media papin dan koja ini dapat digunakan sebagai media pembelajaran di sekolah dan perlu adanya pengembangan lebih lanjud. Hal ini bertujuan untuk menghasilkan media yang lebih berkualitas dan inovatif.
\end{abstract}

\section{PENDAHULUAN}

Undang-undang No.20 Tahun 2003 tentang sistem pendidikan nasional masyarakat bahwa "Pendidikan adalah salah satu usaha sadar dan terencana untuk mewujudkan suasana belajar dan proses pembelajaran agar peserta didik secara aktif mengembangkan potensi dirinya untuk memiliki kekuatan spiritual keagamaan, pengendalian diri, kepribadian, kecerdasan, ahlak mulia, serta keterampilan yang diperlukan dirinya, masyarakat, bangsa dan negara.

Pendidikan merupakan hal penting bagi setiap manusia. Hal ini dianggap sebagai salah satu cara untuk mengembangkan potensi-potensi yang memiliki setiap individu. Pengembangan pada potensi setiap peserta didik berbeda-beda antara satu dengan lainya. Salah satu cara peningkatan mutu pendidikan melalui pencapaian keberhasilan dalam pembelajaran di kelas. Karena keberhasilan suatu pembelajaran menunjukkan kualitas peserta didik yang bersangkutan.

Menurut Hamdani (2011: 244) bahwa, "Media pembelajaran dalam proses belajar dapat membangkitkan keinginan dan minat yang baru, membangkitkan motivasi dan rangsangan kegiatan belajar, bahkan membawa pengaruh-pengaruh psikologis terhadap siswa".

Berdasarkan hasil wawancara dengan guru kelas IV yang di lakukan peneliti di SDN Bugangan 02 Semarang terdapat beberapa masalah yang di hadapi yaity siswa kurang dalam berkonsentrasi, kesulitan memahami materi,siswa tidak memperhatikan guru dan juga kurangnya media benda konkrit yang di gunakan guru saat pembelajaran hanyalah buku dan peralatan seadanya.

Maka yang diperlukan adalah media pembelajaran yang mempunyai tampilan menarik karena siswa kelas IV masih membutuhkan benda kongkrit,bagus dan menarik untuk pembelajaran terlebih 
terdapat gambar-gambar yang menarik perhatian siswa yang sesuai dengan materi yang di ajarkan. Karena di dalam ruang kelas IV belum terdapat LCD untuk program belajar mengajar maka media papin dan koja adalah solusi yang bisa di gunakan untuk sebagai media pembelajaran pada materi pembulatan bilangan di kelas IV SDN Bugangan 02 Semarang.

Berdasarkan latar belakang di atas, peneliti tertarik untuk mengembangkan penelitian dengan judul Pengembangan media papin dan koja (papan pintar dan kotak ajaib) sebagai media pembelajaran matematika siswa kelas IV sekolah dasar. Sesuai dengan rumusan masalah, tujuan yang ingin di capai penulis melalui penelitian pengembangan ini adalah mengetahui kelayakan media Papin dan Koja (papan pintar dan kotak ajaib) sebagai media pembelajaran matematika siswa kelas IV sekolah dasar.

Media Pembelajaran dalam proses belajar mengajar diartikan sebagai alat-alat grafis, photografis, atau elektronis untuk merangkap, memproses, dan menyusun kembali informasi visual atau verbal ( Azhar, 2014:3).

Papan pintar, Menurut dari junal Suharmanto (2014) media papan hitung di kembangkan dengan tujuan agar matapelajaran Matematika Khususnya pada materi pembagian yang terkadang sering dianggap sulit oleh siswa akan lebih menyenangkan, sehingga dalam kegiatan belajar siswa tidak akan merasa cepar bosan, selain itu juga diharapkann dengan media ini dapat membantu siswa dalam proses berhitung. Kotak ajaib Menurut dari Sugeng (2016) kobela adalah akronim dari kotak belajar ajaib. Kotak adalah peti kecil tempat barang-barang perhiasan, barang kecil, dsb (Kamus besar bahasa indonesia).

Menurut Slameto (2013:54) Keberhasilan belajar sangat dipengaruhi oleh beberapa faktor. Faktorfaktor tersebut dapat dikelompokkan menjadi dua kelompok yaitu faktor dalam diri siswa sendiri (intern) dan faktor dari luar siswa (ekstern). Faktor dari dalam siswa yang berpengaruh terhadap hasil belajar diantaranya adalah kecakapan, minat, bakat, usaha, motivasi, perhatian, kelemahan dan kesehatan, serta kebiasaan siswa sedangkan dari luar diri siswa yang mempengaruhi hasil belajar diantarana adalah lingkungan fisik dan non fisik, lingkungan sosial budaya, lingkungan keluarga, progam sekolah, guru, pelaksaan pembelajaran dan teman sekolah.

\section{METODE PENELITIAN}

Jenis penelitian yang digunakan peneliti adalah penelitian dan pengembangan (research and Developmen). "Metode Penelitian dan Pengembangan atau dalam bahasa inggris Reaseach and Development adalah metode penelitian yang digunakan untu menghasilkan produk tertentu, dan menguji keefektifan produk tersebut". (Sugiyono, 2015: 407).

Peneliti memilih jenis $\mathrm{R}$ \& D karena dalam penelitian ini peneliti ingin mengembangkan suatu media pembelajaran yang bernama Papin dan Koja. Media tersebut merupakan pengembangan dari media pembelajaran papan pintar dan kotak ajaib yang dijadikan satu menjadi Papin dan Kojapada materi pembulatan bilangan matematika dengan menggunakan desain 3 dimensi gambar anak bermain angka yang menggabungkan angka-angka dalam soal yang terdapat dalam media papan tersebut. Media ini dikembangkan untuk digunakan pada materi pembulatan kelas IV konsep pembulatan bilangan bulat ke atas dan ke bawah.

Prosedur penelitian pengembangan yang digunakan mengacu pada pengembangan Borg and Gall. Menurut Borg and Gall dalam buku Syaodih (2016: 190), penelitian pengembangan terdiri dari 10 langkah pengembangan yaitu :

Berdasarkan keputusan hasil rapat senat Fakultas, diputuskan bahwa mahasiswa Strata 1 (S1) yang melakukan penelitian dan pengembangan hanya sebatas pada tahap empat atau ke lima yaitu hanya sebatas uji coba lapangan awal dan revisi hasil uji coba berdasarkan analisis uji coba lapangan awal.

Studi pendahuluan dilakukan yaitu wawancara guru kelas IV Sekolah Dasar yaitu SDN Bugangan 02 pada tanggal 10 April 2018 dan menyerahkan angket analisis kebutuhan guru, dan siswa dalam media pembelajaran yang berkaitan dengan materi pembelajaran. Membuat instrument berupa silabus, rencana pelaksanaan pembelajaran, lembar validasi materi, lembar validasi media yang kemudian di lakukan validasi oleh dosen, lembar soal yang sudah divalidasi oleh dosen dan angket tanggapan guru serta siswa terhadap media PAPIN dan KOJA (Papan Pintar dan Kotak Ajaib) pada materi pembulatan angka Matematika.

Pengembangan media pembelajaran yang dilakukan sesuai dengan rancangan yang sudah dilakukan berdasarkan prosedur penelitian pengembangan menurut Sugiyono (2011: 408). Subjek penelitian ini adalah siswa kelas 1 SDN Bugangan 02 Semarang. Sesuai dengan tahapan penelitiannya, maka akan dilaksanakan beberapa tahapan proses pengembilan data. Dalam penelitian ini dilakukan uji coba media, yaitu uji coba produk dengan jumlah siswa 27 anak.

Data kelayakan produk Media Papan Pintar dan Kotak Ajaib ini diperoleh dari validator ahli media dan ahli materi. Data yang dihasilkan dari validator ahli media dan ahli materi yaitu ahli media sebesar 
86,3\% sedangkan dari ahli materi sebesar 82,6\%. Dengan demikian kelayakan produk Media Papan Pintar dan Kotak Ajaib termasuk dalam kategori sangat baik. Hasil pertemuan pertama menunjukkan nilai terendah 10 dan nilai tertinggi 100, yang tidak mencapai KKM berjumlah 14 siswa dengan presentase $54 \%$, sedangkan yang mencapai KKM berjumlah 12 siswa dengan presentase $46 \%$, dari hasil pertemuan pertama tersebut diperoleh nilai rata-rata sebesar 6.15.

Dari hasil pertemuan kedua menunjukkan nilai terendah 20 dan nilai tertinggi 100, terdapat 5 siswa tidak mencapai KKM dengan pesentase 19\% dan 21 siswa mencapai KKM dengan presentase 81\% dengan nilai rata-rata 79,2 .

Pokok temuan yang dihasilkan dalam penelitian pengembangan ini adalah sebagai berikut : 1). Dihasilkan produk pengembangan berupa media pembelajaran Papin dan Koja (papan pintar dan kotak ajaib) dengan menggunakan Team Game Tournaments pada pembulatan siswa kelas IV SD yang valid untuk digunakan sebagai media pembelajaran di kelas IV semester 1. Hasil validasi yang dilakukan oleh ahli media menunjukkan presentase $86,3 \%$ dengan kriteria sangat baik dan hasil dari validasi materi dengan presentase 82,6\% dengan kriteria sangat baik, dan 2) Penggunaan media Papin dan Koja (papan pintar dan kotak ajaib) dengan menggunakan Team game tournaments pada pembulatan siswa kelas IV SD praktis digunakan dalam pembelajaran materi pembulatan kelas IV Sekolah Dasar.

\section{ANALISIS DAN PEMBAHASAN}

Langkah awal yang dilakukan peneliti yaitu mencari potensi dan masalah. Penelitian yang dilaksanakan didasarkan pada potensi dan masalah yang ada di SDN Bugangan 02 Semarang khususnya kelas IV yaitu beberapa masalah yang dihadapi seperti siswa kurang dalam konsentrasi, kesulitan memahami materi, siswa tidak memperhatikan guru, dan kurangnya penggunaan media pembelajaran. Media pembelajaran yang digunakan hanya dari buku paket dan alat peraga sederhana. Tidak jarang siswa kurang tertarik dan malah melakukan kegiatan lain yang tidak berhubungan dengan kegiatan pembelajaran. Akibatnya kelas menjadi tidak kondusif dan hasil belajar tidak sesuai yang diharapkan.

Langkah kedua yaitu peneliti mengumpulkan data, Berdasarkan analisis kebutuhan yang ada di lapangan, peneliti mengembangkan sebuah media pembelajaran Papin dan Koja (Papan Pintar dan Kotak Ajaib) dengan menggunakan metode Team game tournament pada materi pembulatan siswa kelas IV SD yang dikembangkan berdasarkan ide dari peneliti dan sebagai alternatif penggunaan media pembelajaran berbentuk papan angka matematika yang dapat membantu pendidik dan peserta didik di dalam kelas.

Papin dan Koja dikembangkan berdasarkan langkah-langkah penelitian dan pengembangan. Model ini digunakan untuk menghasilkan dan menguji produk tertentu. Media Papin dan Koja (papan pintar dan kotak ajaib) dengan menggunakan Team Game Tournaments pada pembulatan siswa kelas IV SD dibuat untuk menghasilkan produk berupa media pembelajaran.

Tabel 1. Hasil Penilaian Ahli Media

\begin{tabular}{llllll}
\hline No & Aspek Penilaian & Jumlah Skor & Skor Ideal & Presentase & Kriteria \\
\hline 1 & Kesesuaian Produk & 20 & 20 & $100 \%$ & Sangat Baik \\
2 & Kelayakan Produk & 18 & 20 & $90 \%$ & Sangat Baik \\
3 & Kontribusi Produk & 20 & 20 & $100 \%$ & Sangat Baik \\
4 & Keunggulan Produk & 14 & 15 & $93 \%$ & Sangat Baik \\
5 & Kesempurnaan produk & 10 & 10 & $100 \%$ & Sangat Baik \\
& Jumlah Skor & 82 & 95 & $86,3 \%$ & Sangat Baik \\
\hline
\end{tabular}

$$
\begin{aligned}
\text { Presentase } & =\frac{\text { Skor total }}{\text { Skor ideal }} \times 100 \% \\
& =\frac{82}{95} \times 100 \%=86,3 \%
\end{aligned}
$$

Berdasarkan perhitungan Tabel 1 maka diketahui presentase sebesar 86,3\% dikategorikan sangat baik.

Hasil Validasi produk oleh ahli materi

Ahli media yang dimintai kesediannya dalam melakukan validasi produk adalah Ibu Anggun Dwi Setya, S.Pd., M.Pd. Setelah lembar validasi diberikan kepada validator diperoleh data pada tabel sebagai berikut: 
Tabel 2. Hasil Penilaian Ahli Materi

\begin{tabular}{llllll}
\hline No & Aspek Penilaian & Jumlah Skor & Skor Ideal & Presentase & Kriteria \\
\hline 1 & Indikator Kesesuaian & 11 & 15 & $73,3 \%$ & Baik \\
2 & Indikator Kelayakan & 10 & 20 & $80 \%$ & Baik \\
3 & Indikator Penyajian & 8 & 10 & $80 \%$ & Baik \\
4 & Indikator Kompetensi & 27 & 30 & $90 \%$ & Sangat Baik \\
& Jumlah Skor & 62 & 75 & $82,6 \%$ & Sangat Baik \\
\hline
\end{tabular}

$$
\begin{aligned}
\text { Presentase } & =\frac{\text { Skor total }}{\text { Skor ideal }} \times 100 \% \\
& =\frac{62}{75} \times 100 \%=82,6 \%
\end{aligned}
$$
sangat baiK.

Berdasarkan perhitungan Tabel 2. , maka diketahui presentase sebesar $82,6 \%$ dikategorikan

Tabel 3. Kriteria Kelayakan Produk Hasil Analisis Validator Ahli

\begin{tabular}{llll}
\hline No & Dosen Validator & Presentase & Kriteria \\
\hline 1 & Maftukin Huda, S.Pd., M.Pd & $86,3 \%$ & Sangat Baik \\
2 & Anggun Dwi Setya, S.Pd., M.Pd & $82,6 \%$ & Sangat Baik \\
\hline
\end{tabular}

\begin{tabular}{|c|c|c|c|c|c|c|c|}
\hline \multirow[t]{2}{*}{ No } & \multirow[t]{2}{*}{ Aspek Penilaian } & \multirow{2}{*}{$\begin{array}{l}\text { Nomor } \\
\text { Kriteria }\end{array}$} & \multicolumn{2}{|c|}{ Jumlah Skor } & \multirow{2}{*}{$\begin{array}{l}\text { Skor } \\
\text { ideal }\end{array}$} & \multicolumn{2}{|c|}{ Presentase } \\
\hline & & & $\mathrm{Ya}$ & Tidak & & $\mathrm{Ya}$ & Tidak \\
\hline \multirow[t]{2}{*}{1} & Angket Tanggapan siswa & $1-10$ & 252 & 8 & 260 & $97 \%$ & $3 \%$ \\
\hline & Total & & 10 & 0 & 10 & $97 \%$ & $3 \%$ \\
\hline
\end{tabular}

Tabel. 4. Hasil Penilaian Respon 26 Siswa

$$
\begin{gathered}
\text { Presentase }=\frac{\text { jumlah skor }}{\text { skor ideal }} \times 100 \% \\
=\frac{252}{260} \times 100 \%=97 \%
\end{gathered}
$$

\section{KESIMPULAN}

Berdasarkan hasil penelitian yang dilakukan, dapat disimpulkan bahwa:

Pengembangan media Papin dan Koja (papan pintar dan kotak ajaib) dengan menggunakan Team Game Tournaments pada Pembulatan Siswa kelas IV SD. Hasil validasi oleh ahli media diperoleh presentase sebesar 86,3\% dengan kriteria sangat baik, hasil validasi oleh ahli materi diperoleh presentase sebesar 82,6\% dengan kriteria sangat baik dan angket tanggapan siswa SDN Bugangan 02 Semarang dengan presentase $97 \%$.

Penggunaan media Papin dan Koja (papan pintar dan kotak ajaib) dengan menggunakan Team Game Tournaments pada pembulatan Siswa kelas IV SD praktis melihat dari hasil nilai dari pertemuan pertama dan kedua dengan rata-rata hasil belajar sebesar 61,5 dengan ketuntasan sebesar $46 \%$ dan pertemuan kedua dengan rata-rata hasil belajar sebesar 79,2 dengan ketuntasan sebesar 81\%.

Berdasarkan hasil penelitian yang diperoleh, maka peneliti memberikan saran sebagai pertimbangan untuk perbaikan media dan kegiatan pembelajaran sebagai berikut: 1. Perlu adanya pengembangan lebih lanjut mengenai media Papin dan Koja (papan pintar dan kotak ajaib) serta menerapkan konsep pembulatan yang berbeda sehingga menghasilkan media yang lebih inovatif dan berkualitas, 2. Pemanfaatan media Papin dan Koja (papan pintar dan kotak ajaib) oleh guru diharapkan dapat dikembangkan pada bahasan model pembelajaran lain agar dapat mengembangkan pemahaman siswa, 3. Perlu adanya penyempurnaan lebih lanjut pada konsep dan pengembangan audio sehingga lebih efektif. 


\section{DAFTAR PUSTAKA}

Aryawan, dkk. 2015. Pengembangan Multimedia Interaktif dengan Model Waterfall pada Mata Pelajaran IPAKelasVII. E-Journal Edutech Universitas Pendidikan Ganesha, 3(1).

Arsyad, Azhar. 2011. Media Pembelajaran. Jakarta: PT Raja Grafindo Persada 2014. Media Pembelajaran, Jakarta: PT Raja Grafindo Persada

Eka, dkk. 2013. Pengembangan Media Pembelajaran Fisika Menggunakan Pengembangan Media Pembelajaran Menggunakan Adobe Flash untuk Meningkatkan Hasil Belajar PKn10

Hamdani. 2011. Strategi Belajar Mengajar. Bandung: CV Pustaka Setia.

Harnanto, S. 2016."Alat Peraga Kotak Belajar Ajaib (KOBELA) Dalam Pembelajaran Matematika Materi Perkalian dan Pembagian Sekolah Dasar".http://jurnal.unissula.ac.id/index.php/pendas/article/view/738/0(kamis, tanggal 26 oktober 2017, jam 09.15 PM)

Gd Tuning Putra dkk. 2013. Pengembangan Media Pembelajaran Dreamweaver Model Tutorial pada Mata Pelajaran Mengelola Isi Halaman Web Untuk Siswa Kelas XI Program Keahlian Multimedia di SMK Negeri 3 Singaraja. Journal Undiksha

Peraturan Menteri Pendidikan Nasional Republik Indonesia Nomro 22 Tahun 2006 tentang Standar Isi untuk Satuan Pendidikan Dasar.

Pujiastuti, Desy, Ali. I, \& Emosda. 2014. Pengembangan Media Pembelajaran PKn Berbasis Multimedia Interaktif untuk SMP Kelas VIII. Teknopedagogi,4(1).

Said, Asnah. 2012. Pengembangan Multimedia Pembelajaran pada Mata KuliahPenelitian Tindakan Kelas (PTK) di UPBJJ-UT Medan. Jurnal TeknologiPendidikan 5(2): 149-166.

Setiasih, Windy Agus \& Dimara. K. H. 2012. Pengembangan Media Pembelajaran Biologi Pokok Bahasan Ekosistem Guna Peningkatan Prestasi Siswa Kelas VII SMP Negeri 2 Sumbang. JUITA, 2(1): 9-20.

Slameto. 2013. Belajar dan Faktor yang mempengarui. Jakarta. Rineka Cipta.

Sugiyono.2014. Statistika untuk Penelitian. Bandung: Alfabeta.Sugiyono. 2015. Metode Penelitian Pendidikan. Bandung: Alfabeta.

Sugiyono. 2015. Metode Penelitian dan Pengembangan. Bandung: AlfabetaSukardi. 2014. Metodologi Penelitian Pendidikan. Yogyakarta: Bumi Aksara.

Sugiyono. 2011. Metode Penelitian Kuantitatif, Kualitatif dan R\&N. Bandung: Alfabeta, cv.

Suharmanto. 2014."Pengembangan Media Pembelajaran Papan Hitung Pembagian Pada Mata Pelajaran Matematika Sekolah Dasar Kelas 2".

Sukmadinata, syaodih. 2016. Metode Penelitian Pendidikan. Bandung: PT Remaja Rosdakarya

Undang-Undang No 20 Tahun 2003 Tentang Sistem Pendidikan Nasional

Undang-Undang Dasar Negara Republik Indonesia Tahun 1945 tentang Fungsi Pendidikan Nasional.

Undang-Undang Nomor 20 Tahun 2003 tentang Sistem Pendidikan Nasional.

Ziden, Azidah Abu dan M.F.A Rahman. 2013. The Effectiveness of Web-BasedMultimedia Application Simullation in Teaching and Learning. International Journal of Instruction, 6(2): 211 